\title{
Video Technique for Human Robot-Assisted Microsurgical Vasovasostomy
}

Sijo Parekattil, M.D.

Department of Urology, University of Florida, Gainesville, Florida.

Email: sijo.parekattil@urology.ufl.edu

Hany N. Atalah, M.D.

Department of Urology, University of Florida, Gainesville, Florida.

Marc S. Cohen, M.D.

Department of Urology, University of Florida, Gainesville, Florida.

(c) Mary Ann Liebert, Inc. DOI: 10.1089/vid.2010.0013
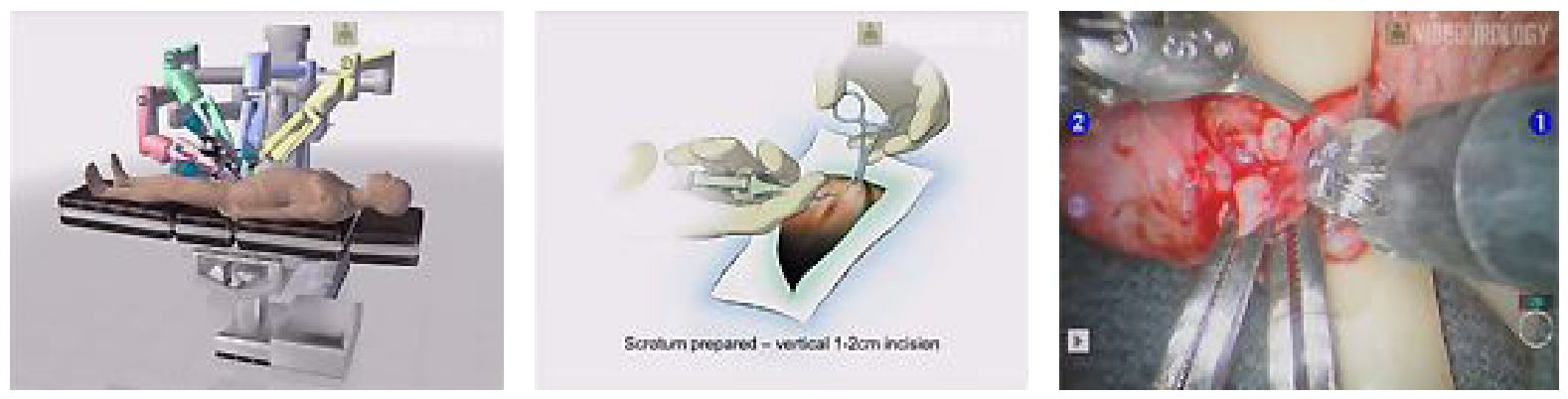

\begin{abstract}
Previous studies have shown that robot-assisted microsurgical vasovasostomy (RAVV) has technical advantages over pure microscopic vasovasostomy (MVV) in animal and human models. This study presents a technique video and initial results for RAVV in 20 human cases compared with $7 \mathrm{MVV}$ cases by a single fellowship-trained microsurgeon from July 2007 to June 2009. A three-layer 10-0 and 9-0 suture anastomosis was performed with up to 22 months of follow-up (mean, 3 months). Mean operative duration for the RAVV cases was 109 and for the MVV was 128 min $(p=0.09)$. At 2 months post-op, all patients were patent. Mean sperm count was 54 million in RAVV and 11 million in MVV $(p=0.04)$. The use of robotic assistance in microsurgical vasovasostomy may have potential benefit over MVV in decreasing operative duration and significantly improving early semen analysis measures. Further evaluation and longer follow-up is needed to assess its clinical potential.
\end{abstract}

The authors have nothing to disclose.

Runtime of video: 9 min $39 \mathrm{sec}$

\section{Cite this video}

Sijo Parekattil, Hany N. Atalah, Marc S. Cohen, Video Technique for Human Robot-Assisted Microsurgical Vasovasostomy, Journal of Endourology. Part B Videourology. 2010, DOI: 10.1089/vid.2010.0013.

Published: 2010 